\title{
Para-(aza,thio)xanthenylated anilines in the pereaminination reaction
}

\author{
(C) Valery Yu. Gorokhov, ${ }^{*+}$ and Tatiana V. Makhova \\ Department of General Chemistry. Federal State Budgetary Educational Institution of Higher Education \\ «Perm State Agro-Technological University named after Academician D.N. Pryanishnikov». \\ Petropavlovskaya St., 23. Perm, 614000, Perm Region. Russia. \\ Phone:+7 (342)217-92-25.E-mail: gorokhov_V.Yu@mail.ru
}

\begin{abstract}
*Supervising author; ${ }^{+}$Corresponding author
Keyword: transamination, substituted $N$-benzylidenanilines, $4-(9 H$-xanthen-9-yl)aniline, 4-(9H-thioxanthen-9-yl)aniline, 4-(5H-benzopyrano[2,3-b]pyridin-5-yl)aniline.
\end{abstract}

Abstract
It is known that the biochemical enzymatic reaction of the reversible transfer of an amino group from an amino-acid to a keto-acid is called a transamination reaction. However, the transamination reaction is applicable not only for biochemical enzymatic reactions, but is also often used in organic synthesis to produce aromatic azomethines.

As objects of study in the transamination reaction, we selected substituted $N$-benzylidenanilines (imines, Schiff bases) and anilines, containing a biologically active heterocyclic fragment in the para-position of the aniline ring. We have shown the feasibility of transamination of substituted $N$-benzylidenanilines ( $N$-benzylidenaniline, $\mathrm{N}$-benzyliden-4-(5H-benzopyrano[2,3-b]pyridin-5-yl)aniline, $\quad N$-benzyliden-4-methoxyaniline), heterocyclic anilines (4-(9H-xanthen-9-yl)aniline, 4-(9H-thioxanthen-9-yl)aniline or 4-(5H-benzopyrano[2,3-b]pyridin-5yl)aniline).

It was found that the interaction of 4-(9H-xanthen-9-yl)aniline, 4-(9H-thioxanthen-9-yl)aniline or 4(5H-benzopyrano[2,3-b]pyridin-5-yl)aniline with $N$-benzylidenanilines, the imine aniline cycle is replaced by the corresponding fragment of heterylated aniline, with the formation of new N-benzylidenanilines, the structure of which is proved by a breakdown of mixed melting and $\mathrm{H}^{1}$ NMR spectroscopy. However, the transamination reaction does not proceed with the use of $\mathrm{N}$-benzyliden-4-methoxyaniline. This, apparently, is associated with the presence of an electron-donating substituent at the para-position of the aniline imines fragment.

Thus, a series of activity of the studied compounds in the transamination reaction of substituted anilines was experimentally established. The most active of these is 4-methoxyaniline, followed by $4-(9 H$-xanthen-9yl)aniline, 4-(9H-thioxanthen-9-yl) aniline, 4-(5H-benzopyrano[2,3-b]pyridin-5-yl)aniline, and closes the series of the least active, unsubstituted aniline.

The synthesis method proposed in this work allows one to obtain new substituted $N$-benzylidenanilines, and the studied series of activity allows one to predict the behavior of anilines containing various electrondonating and electron-withdrawing substituents in the transamination reaction with $N$-benzylidenanilines.

\section{References}

[1] A.E. Braunstein, M.G. Kritzman. The formation of amino acids by intermolecular transfer of an amino group. Bull. Exp. Biol. Med. 1937. Vol.3. P.246-248. (russian)

[2] W.P. Jencks. Catalysis in chemistry and enzymology. N.Y.: Dover, Cop. 1987. 836p.

[3] S. Patai. The chemistry of the carbon-nitrogen double bond. John Wiley \& Sons Ltd. London. 1970. 794p.

[4] F. Schaufelberger, L. Hu, O. RamstrÖm. Trans-Symmetric Dynamic Covalent Systems: Connected Transamination and Transimination Reactions. Chem. Eur. J. 2015. No.21. P.9776-9783.

[5] K.A. Ovchinnikov. Synthesis and chemical properties of adamantane azomethines. Abstract. diss. Samara. 2011. 22p. (russian)

[6] C. Weygand, Hilgetag G. Methods of experiments in organic chemistry. Moscow: Khimiya. 1968. 944p. (russian)

[7] D. Barton, V.D. Ollis. General organic chemistry. Volume 3: Nitrogen-containing compounds. Ed. N.K. Kochetkov, L.V. Baku. Moscow: Chemistry. 1982. 736p. (russian)

[8] L.P. Yunnikova. Interaction of $N$-benzylidenanilines with xanthene. Zh. Org. Khim. 1995. Vol.31. No.1. P.76-79. (russian) 
[9] L.P. Yunnikova. Reductive heterylation of imines with thioxanthene. Chem. Heterocyclic Compd. 1995. No.7. P.1003-1005. (russian)

[10] V.Yu. Gorokhov, L.P. Yunnikova, T.V. Makhova, and G.A. Aleksandrova. Synthesis of $N$-aryl(heteryl) methylene-[4-(5H-chromeno[2,3-b] pyridine-5-il)phenyl]amines and their antimycobacterial activity. Butlerov Communications. 2012. Vol.32. No.10. P.27-29. ROI: jbc-02/12-32-10-27

[11] V.Yu. Gorokhov, and S.M. Shchurenko. Imines with fragments of (aza,tio)xanthenes. Butlerov Communications. 2014. Vol.39. No.8. P.91-93. jbc-02/14-39-8-91 